\title{
Comparative Study Between Systemically and Perineurally Administered Tramadol as an Adjunct in Ultrasound Guided Supraclavicular Brachial Plexus Block
}

\author{
Ahmed Alsaied Abd Elrahman ${ }^{1}$, Huda Fahmy Mahmoud ${ }^{2}$, Nagwa Mohamed Gamal Eldin ${ }^{2}$, Eman \\ Mohamed Sobhy Abd Elshakoor 2* \\ ${ }^{1}$ Anesthesia, Surgical Intensive Care and Pain Medicine Deparmtent, Suhag University. \\ ${ }^{2}$ Anesthesia and Surgical Intensive Care Department, Aswan University \\ * Corrosponding Author: Eman Mohamed Sobhy Abd Elshakoor, E-mail: Nubiankandake@ gmail.com
}

\begin{abstract}
Background: brachial plexus block remains the only practical alternative to general anesthesia for significant surgery on the upper limb. It can be extremely useful in patients with significant co-morbidities such as severe respiratory and cardiovascular disease, morbid obesity and in those with potential airway difficulties.
\end{abstract}

Aim of the Work: comparing the efficacy of systemically administered tramadol and perineurally administered tramadol as an adjunct to bupivacaine in supraclavicular brachial plexus blocks on onset of sensory, motor blockade and postoperative analgesia along with demand for rescue analgesic in the postoperative period.

\section{Patients and Methods:}

- Group A: bupivacaine 0.5\%-20 ml + lidocaine 2\% -5 ml for block.

- Group B: bupivacaine 0.5\%-20 ml + lidocaine 2\% -5 ml mixture for block and tramadol (100 mg) diluted to $10 \mathrm{ml}$ intravenously.

- Group C: bupivacaine 0.5\%-20 ml+ lidocaine 2\% -5 ml+ tramadol (100 mg).

Results: In motor onset block there was a highly significant difference between the three study groups. Also, it was highly significant faster in group $\mathrm{C}$ where tramadol given perineurally compared with those of placebo and systemic tramadol administrations. Duration of sensory block there was a highly significant difference between the three study groups. It was highly significant longer in group $\mathrm{C}$ where tramadol given perineurally compared with those of placebo and systemic tramadol administrations. Regarding First request of rescue analgesia there was a highly significant difference between the three study groups.

Conclusion: the mixture of tramadol, bupivacaine and lidocaine injected perineurally for supraclavicular brachial plexus block hastens the onset of sensory block, motor block and provides a longer duration of motor blockade and postoperative analgesia as compared to other two groups in which tramadol was either injected intravenously (systemic group) or was not given at all (control group).

Keywords: Systemically and Perineurally Administered Tramadol, Supraclavicular Brachial Plexus Block

\section{INTRODUCTION}

Brachial plexus block remains the only practical alternative to general anesthesia for significant surgery on the upper limb. It provides a superior quality of analgesia and avoids the common side-effects associated with general anesthesia such as postoperative nausea and vomiting. It can be extremely useful in patients with significant comorbidities such as severe respiratory and cardiovascular disease, morbid obesity and in those with potential airway difficulties. In addition, it simplifies the management of other disease conditions such as diabetes mellitus, where perioperative fasting can be minimized, diet more easily reintroduced and conscious level continuously monitored. These blocks are therefore particularly useful in the ambulatory surgical setting for a wide variety of patients and procedures. For more complex major procedures, continuous catheter techniques allow prolongation of analgesic block with earlier mobilization, improved rehabilitation, and the potential to reduce hospital stay and improve functional outcome ${ }^{(\mathbf{1})}$.

Local anesthetics alone for supraclavicular brachial plexus block provide good operative 
conditions but have shorter duration of postoperative analgesia. So various adjuvants like opioids, clonidine, neostigmine, midazolam, etc. were added to local anesthetics in brachial plexus block to achieve quick, dense and prolonged block (2).

Tramadol, a 4 phenyl-piperidine analog of codeine has been found to have a unique mechanism of action that suggests its efficacy as an adjunct to local anesthetics in brachial plexus block. Tramadol was tried as an adjunct to local anesthetics in the past, but many studies have been contradictory and inconclusive ${ }^{(3)}$.

Tramadol is an analgesic with mixed opioid and nonopioid activity. Tramadol seems to pass the neuronal membrane and diffuse within the interstitial or axonal fluid since it is a lipophilic drug ${ }^{(4)}$.

The non-opioid activity is through alpha two agonist mechanism and serotonin and noradrenaline reuptake inhibition in central nervous system. It inhibits the reuptake of norepinephrine and serotonin from the nerve endings, and it is supposed to potentiate the effect of local anesthetics when mixed together ${ }^{(5)}$.

\section{AIM OF THE WORK}

To compare the efficacy of systemically administered tramadol and perineurally administered tramadol as an adjunct to bupivacaine in supraclavicular brachial plexus blocks on onset of sensory, motor blockade and postoperative analgesia along with demand for rescue analgesic in the postoperative period.

\section{PATIENTS AND METHODS}

After approval of the ethical committee, this prospective controlled, comparative study was performed in Aswan University Hospital on 60 patients who were scheduled for forearm or hand surgery.

\section{Patients allocated into 3 equal groups:}

- Group A: bupivacaine 0.5\%-20 ml + lidocaine $2 \%-5 \mathrm{ml}$ for block.

- Group B: bupivacaine 0.5\%-20 ml + lidocaine $2 \%-5 \mathrm{ml}$ mixture for block and tramadol (100 $\mathrm{mg}$ ) diluted to $10 \mathrm{ml}$ intravenously.

- Group C: bupivacaine 0.5\%-20 ml+ lidocaine $2 \%-5 \mathrm{ml}+$ tramadol (100 mg).

\section{Inclusion criteria:}

- Patients who undergone hand and forearm surgery.

- Age: between 20 and 60.

- Both genders.

- ASA I/II patients.

Exclusion criteria:

- Had bleeding disorders.

- Got opioid analgesics or monoamine oxidase inhibitors prior to surgery.

- Local infections at the site where needle for block is to be inserted.

- History of seizures.

- Respiratory or cardiac diseases.

- Pregnancy.

- Patients in whom the block effect was partial and required supplementary anesthesia.

\section{Preoperative Assessment and Preparation:}

A careful of medical history was done. General examination (heart rate, arterial blood pressure) and physical examination (chest, heart, abdomen, site of injection and other systems) were carried out. Routine investigations were done. Explanation of visual analogue scale was done to patients (the VAS is consisted of a straight, vertical $10-\mathrm{cm}$ line; the bottom point represented "no pain" $=(0 \mathrm{~cm})$ and the top "the worst pain you could ever have" $=(10 \mathrm{~cm})$. All patients received nothing per oral for at least $6 \mathrm{hr}$. before the procedure. They were tested for local anesthetic sensitivity. On arrival to the operation theatre, standard monitoring was established with starting of peripheral intravenous (I.V) line by $18 \mathrm{G}$ cannula in the contralateral hand and ringer lactate infusion started and patient was sedated with fentanyl 50 micg iv + midazolam $1 \mathrm{mg}$ iv.

\section{Ultrasound guided supraclavicular brachial plexus block:}

\section{Technique.}

First locating the subclavian artery in the short axis view, where the artery appears as a round pulsating, hypoechoic structure. At this point, the hyerechoic first rib is apparent underneath the artery and possibly, the pleura. Lateral to the subclavian artery the operator appreciated the middle scalene, which is notable for its often-striated appearance. Inbetween the subclavian and middle scalene lied divisions of brachial plexus, which appeared as 
hypoechoic grape-cluster-like structure. The block needle was advanced under constant visualization in an in-plane fashion along the medial border of middle scalene, toward the lateral portion of the plexus.

A test dose revealed spread of the anesthesia in fascial layer surrounding the divisions of the brachial plexus.

\section{Patient evaluation:}

We evaluated onset, quality and duration of sensory and motor block along with side effects if any.

1- Duration of Surgery: Time required for the surgical procedure will be assessed by hours.

\section{2- Quality of block:}

\section{*Onset time of sensory block (min.):}

After injection of the solution (time zero) every patient was checked in the following times: 0 , $5,10,20,30$ and 60 minutes for onset of sensory blockade using pinprick test using the following scale (three-point scale):

- 0 points $=$ pinprick perceived as painful (normal sensation).

- 1 point $=$ analgesia to pinprick (blunted sensation).

- 2 points $=$ anesthesia to pinprick (no perception)

3- Visual analogue scale (VAS) for first 24 hours:

Pain intensity was assessed using VAS. The VAS is consisted of a straight, vertical $10-\mathrm{cm}$ line; the bottom point represented "no pain" $=(0 \mathrm{~cm})$ RESULTS and the top "the worst pain you could ever have" = $(10 \mathrm{~cm})$. Patients were asked to make a horizontal mark across the line at the place that indicated the amount of their pain sensation. Measurement of the line in centimeters from the 0 point provided the score. Patients were asked to rate their pain intensity before the block at 1, 2, 4, 6, 12, 18 and 24 hours after the block.

\section{4- Time to first analgesic request ( $\mathrm{Hr}$.):}

It was recorded at the time from the supraclavicular brachial plexus block administration to the patient's first request for analgesic medication.

\section{5- Total analgesic consumption in 24 hours:}

Total amount of supplemental analgesia (in $\mathrm{mg}$ ) required in the first 24 hours after operation was assessed by milligrams of diclofenac sodium required.

\section{6- Adverse effects:}

Possible complications were recorded during the operation and for 24 hours postoperative such as local hematoma, hemothorax, pneumothorax, Horner's syndrome, recurrent laryngeal nerve block, intravascular injection, nausea, vomiting, any signs of local anesthetic toxicity and hallucinations.

The data was analyzed using IBM SPSS Statistics 24.0 program. Screening for extreme values in quantitative variables were done using one-way ANOVA. Discrete and categorical variables were screened using frequency distribution, Chi-square test.

Table (1): Onset of block of the studied groups.

\begin{tabular}{|l|l|c|c|c|c|}
\hline \multicolumn{2}{|c|}{ Onset of block in mintes } & Group A n=20 & Group B n=20 & Group C n=20 & P-VALUE \\
\hline \multirow{4}{*}{ Sensory block } & Mean & 20.75 & 23.00 & 15.50 & $0.032^{*}$ \\
& SD & 10.91 & 10.43 & 3.94 & P1:0.433n.s \\
& Range & $10-60$ & $15-60$ & $10-20$ & P2:0.071n.s \\
& Median & 20.00 & 20.00 & 15.00 & P3:0.011* \\
\hline \multirow{3}{*}{ Motor block } & Mean & 20.0 & 22.5 & 12.0 & $0.001^{* *}$ \\
& SD & 7.25 & 5.96 & 4.97 & P1:0.203n.s \\
& Range & $10-30$ & $15-30$ & $5-20$ & P2:0.001** \\
& Median & 17.50 & 20.00 & 10.00 & P3:0.001** \\
\hline
\end{tabular}

p- value for one way ANOVA test; $\mathrm{p}_{1}$ : $\mathrm{p}$ value for LSD post hoc test for comparing between group A and group $\mathrm{B} ; \mathrm{p}_{2}$ : $\mathrm{p}$ value for LSD post hoc test for comparing between group A and group $\mathrm{C} ; \mathrm{p}_{3}: \mathrm{p}$ value for LSD post hoc test for comparing between group $\mathrm{B}$ and group $\mathrm{C}$; ${ }^{*}$ Statistically significant at $\mathrm{p} \leq 0.05\left({ }^{*}\right.$ mild, ${ }^{* *}$ moderate, ${ }^{* * *}$ highly); n.s: non-significant. 
As regarding onset of sensory block there was significant difference between the three studied groups $(\mathrm{P}=0.032)$. Also, it was significantly faster in group $\mathrm{C}$ than group $\mathrm{B}(\mathrm{P}=0.011)$, But non-significantly faster in group $\mathrm{C}$ than group $\mathrm{A}$ and group $\mathrm{A}$ than group $\mathrm{B}$. As regarding onset of motor block there was a highly significant difference between the three study groups $(\mathrm{P}=0.001)$. Also it was highly significant faster in group $\mathrm{C}$ than group A and group $\mathrm{B}(\mathrm{P}=0.001$ both), non-significantly faster in group $\mathrm{A}$ and group $\mathrm{B}$.

Table (2): Duration of block of the studied groups.

\begin{tabular}{|l|l|c|c|c|c|}
\hline \multicolumn{2}{|c|}{ Duration of block in hours } & Group A n=20 & Group B n=20 & Group C n=20 & P-VALUE \\
\hline \multirow{4}{*}{ Sensory block } & Mean & 5.30 & 5.10 & 9.20 & $<0.000^{* *}$ \\
& SD & 1.750 & 1.518 & 2.19 & P1:0.732n.s \\
& Range & $2-8$ & $2-8$ & $6-12$ & P2:0.001** \\
& Median & 6.00 & 6.00 & 8.00 & P3:0.001** \\
\hline \multirow{5}{*}{ Motor block } & Mean & 5.90 & 5.70 & 9.80 & $0.001^{* *}$ \\
& SD & 1.37 & 1.49 & 2.33 & $\mathrm{P} 1: 0.724 \mathrm{n} . \mathrm{s}$ \\
& Range & $4-8$ & $4-8$ & $6-12$ & P2:0.001** \\
& Median & 6.00 & 6.00 & 10.00 & $\mathrm{P} 3: 0.001^{* *}$ \\
\hline
\end{tabular}

As regarding duration of sensory block there was a highly significant difference between the three study groups $(\mathrm{P}=0.001)$. It was highly significant longer in group $\mathrm{C}$ compared with group $\mathrm{A}$ and group $\mathrm{B}(\mathrm{P}=0.001$ both). As regarding duration of motor block there was a highly significant difference between the three study groups $(\mathrm{P}=0.001)$. Also, it was highly significant longer in group $\mathrm{C}$ compared with group $\mathrm{A}$ and group $\mathrm{B}$.

Table (3): Comparison of VRS among studied groups.

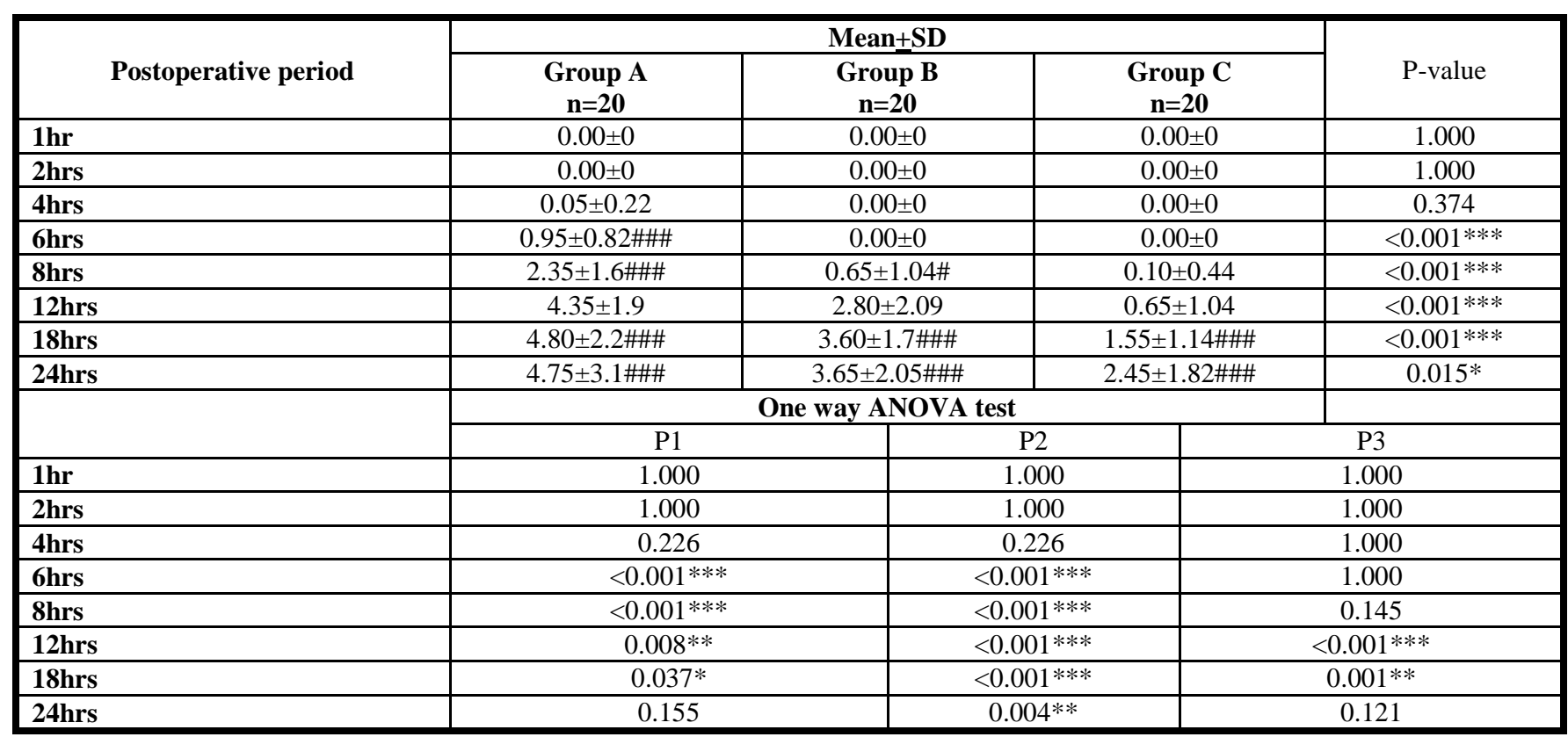

\#: significant difference from basal value among each group individually at $<0.05$ ( ${ }^{\#}$ mild, ${ }^{\# \#}$ moderate, ${ }^{\# \#}$ highly).

Table (4): Comparison of request for rescue analgesia among studied groups.

\begin{tabular}{|l|c|c|c|c|}
\hline \multicolumn{1}{|c|}{ Rescue analgesia } & Group A n=20 & Group B n=20 & Group C n=20 & P-VALUE \\
\hline Yes $\mathrm{n}(\%)$ & $17(85 \%)$ & $15(75 \%)$ & $5(25 \%)$ & \multirow{2}{*}{$0.000 * * *$} \\
\hline No $\mathrm{n}(\%)$ & $3(15 \%)$ & $5(25 \%)$ & $15(75 \%)$ & \\
\hline
\end{tabular}

Fisher exact test; $\mathrm{p}$-value is considered significant at $<0.05$.

There was no request for rescue analgesia in three patients (15\%) in group A, five patients $(25 \%)$ in group B, and fifteen patients (75\%) in group C within 24 hrs postoperative. It was statistically significant decreased in group $\mathrm{C}$ compared with group $\mathrm{A}$ and $\mathrm{B}$. 
Table (5): Comparison of first request for rescue analgesia among studied groups.

\begin{tabular}{|c|c|c|c|c|}
\hline First analgesic request & Group A n=20 & Group B n=20 & Group C n=20 & P-VALUE \\
\hline 8 hr. & $5(25 \%)$ & $0(0 \%)$ & $0(0 \%)$ & $0.001 * * *$ \\
\hline $12 \mathrm{hr}$ & $10(50 \%)$ & $4(20 \%)$ & $0(0 \%)$ & Pi:0.003** \\
\hline $18 \mathrm{hr}$ & $2(10 \%)$ & $7(35 \%)$ & $0(0 \%)$ & Pii:0.001*** \\
\hline $24 \mathrm{hr}$ & $0(0 \%)$ & $4(20 \%)$ & $5(25 \%)$ & Piii:0.001*** \\
\hline
\end{tabular}

Analysis of qualitative data by chi-squared test; $\mathrm{p}$-value is considered significant at $<0.05$; $\mathrm{p}_{\mathrm{i}}$ : $\mathrm{p}$ value for Fisher exact test for comparing between group A and group B; $p_{i i:}$ p value for Fisher exact test for comparing between group $\mathrm{A}$ and group $\mathrm{C}$; $\mathrm{p}_{\mathrm{iii}}$ : $\mathrm{p}$ value Fisher exact test for comparing between group $\mathrm{B}$ and group $\mathrm{C}$.

There was a highly significant difference between the three study groups $(\mathrm{P}=0.001)$ regarding the first request for rescue analgesia. It was highly significant delayed in group $\mathrm{C}$ compared with group $\mathrm{A}$ and group $\mathrm{B}$ $(\mathrm{P}=0.001$ both) and moderately significant delayed in group $\mathrm{B}$ than with group $\mathrm{A}(\mathrm{P}=0.003)$.

Table (6): Comparison of total analgesic dose postoperatively among studied groups.

\begin{tabular}{|l|c|c|c|c|}
\hline \multicolumn{1}{|c|}{ Total analgesic Diclofenac Na dose in $\mathbf{m g}$} & Group A n=20 & Group B n=20 & Group C n=20 & P-VALUE \\
\hline & & & $0.001^{* *}$ \\
Mean \pm SD & $176.47 \pm 52.6$ & $135.00 \pm 58.09$ & $75 \pm 0.00$ & $\begin{array}{c}\mathrm{P} 1: 0.031^{*} \\
\mathrm{P} 2: 0.001^{* *} \\
\mathrm{P} 3: 0.032^{*}\end{array}$ \\
\hline
\end{tabular}

Analysis of quantitative data by ANOVA test; $\mathrm{p}_{1}: \mathrm{p}$ value for LSD post hoc test for comparing between group A and group B; $\mathrm{p}_{2}$ : $\mathrm{p}$ value for LSD post hoc test for comparing between group A and group C; $\mathrm{p}_{3}$ : $\mathrm{p}$ value for LSD post hoc test for comparing between group $\mathrm{B}$ and group $\mathrm{C}$.

As regarding total rescue analgesic dose given there was a moderately significant difference between the three study groups $(\mathrm{P}=0.001)$. It was moderately significant smaller in group $\mathrm{C}$ compared with group $\mathrm{A}(\mathrm{P}=0.001)$ and compared with group $\mathrm{B}$ it was mildly significant smaller $(\mathrm{P}=0.032)$, while it was mildly significant smaller in group $\mathrm{B}$ compared with group $\mathrm{A}(\mathrm{P}=0.031)$.

\section{DISCUSSION}

Brachial plexus block remains the only practical alternative to general anesthesia for significant surgery on the upper limb. It provides a superior quality of analgesia and avoids the common side-effects associated with general anesthesia such as postoperative nausea and vomiting. It can be extremely useful in patients with significant co-morbidities such as severe respiratory and cardiovascular disease, morbid obesity and in those with potential airway difficulties. In addition, it simplifies the management of other disease conditions such as diabetes mellitus, where perioperative fasting can be minimized, diet more easily reintroduced and conscious level continuously monitored. These blocks are therefore particularly useful in the ambulatory surgical setting for a wide variety of patients and procedures. For more complex major procedures, continuous catheter techniques allow prolongation of analgesic block with earlier mobilization, improved rehabilitation, and the potential to reduce hospital stay and improve functional outcome ${ }^{(\mathbf{1})}$.

The brachial plexus block consists of injecting local analgesic drugs in the fascial spaces surrounding the nerve plexus, thereby blocking the autonomic, sensory and motor fibers supplying the upper extremity. It is a simple, safe and effective technique of anesthesia having distinct advantages over general and intravenous regional anesthesia. A regional technique should always be considered whenever general condition of the patient is poor, or the patient is not adequately prepared or in the presence of associated condition like uncontrolled diabetes, cardiovascular or respiratory diseases. It is also useful when the patient prefers to retain his consciousness during surgery and when it is important for the patient to remain ambulatory ${ }^{(6)}$.

Supraclavicular brachial plexus block is widely employed regional nerve block to provide anesthesia and analgesia for the upper extremity surgery. It provides a rapid, dense and predictable anesthesia of the entire upper extremity in the most consistent manner of any brachial plexus technique. It is carried out at the "division" level of the brachial plexus; with high volume the "trunk" level of the plexus may also be blocked in this approach. Perhaps that is why there is often little or no sparing 
of peripheral nerve if an "adequate" paresthesia or stimulation is obtained ${ }^{(7)}$.

Currently available local anesthetics can provide analgesia for limited period of time when used as single injection. To extend the analgesia period beyond the operating rooms, various methods have been tried with the aim of prolonging the local anesthetic action, like continuous infusion of local anesthetics via indwelling catheters, use of different adjuvants with local anesthetics including epinephrine, clonidine, opioids, ketamine, midazolam and dexamethasone ${ }^{(7)}$.

The central and peripheral analgesic effects of tramadol have not been fully explained ${ }^{(\mathbf{8 , 9})}$. The monoaminergic activity of tramadol enhances the inhibitory activity of the descending pain pathways, resulting in a suppression of nociceptive transmission at the spinal level ${ }^{(\mathbf{1 0})}$.

Tsai et al. (11) showed that Sensory block following perineural administration of tramadol to the human sural nerve developed only after a concentration of $1-1.5 \%$ is used. A sensory block for only 5 minutes occured in one out of six subjects with $0.5 \%$ tramadol.

Mert et al. (12) compared the nerve conduction blockade by tramadol and a local anesthetic and concluded that tramadol has a local anesthetic activity similar to lignocaine. Moreover, Güven et al. (13) demonstrated that tramadol may block $\mathrm{K}^{+}$channel more than lignocaine. A further experimental study suggests that the nonspecific voltage dependent $\mathrm{K}+$ channels and the nitrergic system might have a role in the antinociceptive effect of tramadol ${ }^{(14)}$.

An experimental study suggested that tramadol acts on voltage dependent $\mathrm{Na}+$ channels like local anesthetics and adrenergic pathways, like vasoconstrictors as mechanisms of local tramadol effects ${ }^{(15)}$.

Sunita Goel et al. (16) demonstrated that intravenous regional anesthesia (IVRA) tramadol assured significantly longer pain free interval of $16.8 \pm 9.07$ hours $(\mathrm{p}<0.05)$ while ketorolac had $12.9 \pm 8.48$ hours. It shows that tramadol has postoperative analgesic effect and also has a property of preemptive analgesia.

The aim of our study was to compare the efficacy of systemically administered tramadol and perineurally administered tramadol as an adjunct to bupivacaine in supraclavicular brachial plexus blocks on onset of sensory, motor block and postoperative analgesia along with demand for rescue analgesic in the postoperative period.

The study demonstrates that the mixture of tramadol and bupivacaine injected perineurally for supraclavicular brachial plexus block hastens the onset of sensory block, motor block and provides a longer duration of motor blockade and demand for rescue analgesia as compared to other two groups.

As a support to our study results Shin et al. metaanalysis identified 16 randomized controlled trials (RCTs) with 751 patients. Brachial plexus block with perineural tramadol prolonged the duration of sensory block (mean difference [MD], $61.5 \mathrm{~min} ; 95 \% \mathrm{CI},-95.5$ to $-27.6 ; P=0.0004$ ), motor block (MD, $-65.6 \mathrm{~min}$; $95 \% \mathrm{CI},-101.5$ to 29.7; $P=0.0003$ ), and analgesia (MD, -125.5 min;95\% CI, -175.8 to $-75.3 ; P<0.0001)$ compared with BPB without tramadol. Tramadol also shortened the time to onset of sensory block (MD, $2.1 \mathrm{~min} ; 95 \% \mathrm{CI}, 1.1$ to $3.1 ; P<0.0001)$ and motor block (MD, 1.2 min; 95\% CI, 0.2 to $2.1 ; P=0.01$ ). In subgroup analysis, the duration of sensory block, motor block, and analgesia was prolonged for BPB with tramadol $100 \mathrm{mg}(P<0.05)$ but not for BPB with tramadol $50 \mathrm{mg}$. The quality of evidence was high for duration of analgesia according to the GRADE system which is becoming the benchmark for communicating evidence-based medicine throughout the world. Adverse effects were comparable between the studies ${ }^{(\mathbf{1 7})}$.

While Serhan et al. ${ }^{(18)}$ studied 60 patients in a prospective, double-blind randomized study. The axillary plexus blockade in group $\mathrm{L}$ was performed with a combination of $36 \mathrm{~mL}$ of $0.5 \%$ levobupivacaine and $2 \mathrm{~mL}$ of $0.9 \%$ saline. Group LT received the same amount and concentration of levobupivacaine, which was combined with $2 \mathrm{~mL}$ of tramadol $(50 \mathrm{mg} \mathrm{mL}-1)$. Onset times of sensory and motor block, maximum sensory and motor block levels, and times needed to reach to the maximum sensory and motor block levels were similar in both groups and there were no significant differences between the groups in terms of the postoperative NRS scores and postoperative analgesic consumption. This may be explained by local anesthetic (levobupivacaine) which is different from bupivacaine in duration of action. 
Also, Chatopadhyay et al. ${ }^{(19)}$ evaluated the use tramadol $100 \mathrm{mg}$ as an adjuvant to bupivacaine $0.25 \%$, total volume being $40 \mathrm{ml}$, in supraclavicular brachial plexus block given for various upper limb surgeries and concluded that tramadol is a useful adjuvant and reduces the onset time of motor and sensory block and enhances the duration of sensory block, motor block and postoperative analgesia. All parameters were comparable to our study except for the fact that there was no systemic group in their study group.

The results of our study were entirely different from study by Mannion et al. ${ }^{(20)}$ used 1.5 $\mathrm{mg} \mathrm{kg}^{-1}$ tramadol as an additive for psoas compartment blockade with $0.4 \mathrm{~mL} \mathrm{~kg}^{-1}$ of $0.5 \%$ levobupivacaine and compared the results with those of placebo and systemic tramadol administrations. They concluded that the addition of tramadol did not cause any difference, compared to either placebo or bolus systemic administration, except for higher sedation in systemic use.

These results are matched with Antonucci who added tramadol to the longer acting local anesthetics ropivacaine $0.75 \%$ and bupivacaine $0.25 \%$ respectively. Antonucci compared different adjuncts (100 mg tramadol, $1.5 \gamma / \mathrm{kg}$ clonidine, $20 \gamma$ sufentanil) to brachial plexus anesthesia against a control group. This study showed that all three substances reduced the onset time of brachial plexus blockade ${ }^{\text {(21) }}$.

Although Geze et al. ${ }^{(22)}$ revealed that Onset of motor block had no significant difference between the groups in terms of onset of partial and complete motor block, recovery of sensation, return of full motor block this discrepancy from our study may be due to administration of a different type of local anesthetic.

Also, Kaabachi et al. (5) studied 102 patients scheduled for hand surgery under axillary block with lidocaine $1.5 \%$ (epinephrine $1 / 200,000$ ) and the addition of either saline or tramadol (100 $\mathrm{mg}, 200 \mathrm{mg}$ ) revealed significant dose related prolongation of motor and sensory blocks in axillary nerve. However, the onset of the block was delayed with $200 \mathrm{mg}$ of tramadol may be due to the fact that they have used lidocaine with a quicker onset and different pharmacodynamic properties than bupivacaine, which was used in our study.
These findings correlate with the study of Kapral et al. ${ }^{(23)}$ were additional anesthetic effect was observed when adding $100 \mathrm{mg}$ tramadol to the brachial plexus blocks. Therefore, it is unlikely that the prolonged duration of anesthesia was a result of systemic absorption.

Also, Sarihasan et al. (24) concluded that $100 \mathrm{mg}$ tramadol as adjunct to supraclavicular plexus blocks extended the duration of postoperative analgesia.

Siddiqui et al. ${ }^{(25)}$ and Kaushik et al. ${ }^{(26)}$ in their studies about the effects of addition of tramadol to lidocaine for intravenous regional anesthesia in patients undergoing hand surgery. also found that sensory recovery time and motor onset and recovery times were not different between the groups unlike our study; may be as lidocaine has shorter duration of action than bupivacaine.

As regarding first request of rescue analgesia there was a highly significant difference between the three study groups $(\mathrm{P}=0.001)$. Also it was highly significant delayed in group $\mathrm{C}$ than group $\mathrm{A}$ and group $\mathrm{B}(\mathrm{P}=0.001$ both $)$ and moderately significant delayed in group $B$ than with group $\mathrm{A}(\mathrm{P}=0.003)$.

As regarding total rescue analgesic dose given there was a moderately significant difference between the three study groups $(\mathrm{P}=0.001)$. Also, it was moderately significant smaller in group $\mathrm{C}$ than group $\mathrm{A}$ and $\mathrm{B}(\mathrm{P}=0.001, \mathrm{P}=0.032$ respectively).

Most of the researches assess postoperative analgesia and analgesic requirements so we found Robaux et al. ${ }^{(3)}$ confirms our study results via a double blinded RCT to study the dose-effect relationship and determine the optimal dose of tramadol added to brachial plexus anesthesia for carpal tunnel release surgery. All 100 patients received $1.5 \%$ mepivacaine $40 \mathrm{~mL}$ plus a study solution containing either isotonic sodium chloride or tramadol (40 mg, $100 \mathrm{mg}, 200 \mathrm{mg}$ ). This study suggests that tramadol added to $1.5 \%$ mepivacaine for brachial plexus block enhances in a dosedependent manner the duration of analgesia with acceptable side effects.

But Dikmen et al. (27) observed that the addition of $100 \mathrm{mg}$ of tramadol to $3.75 \mathrm{mg} / \mathrm{ml}$ of ropivacaine does not have any beneficial effect on the nerve block characteristics of axillary brachial 
plexus anesthesia for arteriovenous fistula surgery in uremic patients.

In our study, majority of patients $(25 \%)$ in group C required first analgesic after $24 \mathrm{hr}$. of surgery and the delayed requirement of analgesia postoperatively in group $\mathrm{C}$ was statistically significant which correlates with Senel et al. (28) who involved 36 patients who scheduled for forearm and hand surgery under axillary brachial plexus block in a controlled, randomized, doubleblinded study. Group $\mathrm{R}$ received $0.375 \%$ ropivacaine in $40 \mathrm{~mL}$, group $\mathrm{RT}$ received $0.375 \%$ ropivacaine in $40 \mathrm{~mL}$ with tramadol $50 \mathrm{mg}$, and group RK received $0.375 \%$ ropivacaine in $40 \mathrm{~mL}$ with ketamine $50 \mathrm{mg}$ for axillary brachial plexus block. The results of this study suggest that the addition of $50 \mathrm{mg}$ tramadol to $0.375 \%$ ropivacaine for axillary brachial plexus block prolongs the duration of anesthesia and analgesia without increasing side effects, whereas addition of $50 \mathrm{mg}$ ketamine to $0.375 \%$ ropivacaine does not provide any additional effect.

\section{CONCLUSION}

In our study the mixture of tramadol, bupivacaine and lidocaine injected perineurally for supraclavicular brachial plexus block hastened the onset of sensory block, motor block and provided a longer duration of motor blockade and postoperative analgesia as compared to other two groups in which tramadol was either injected intravenously (systemic group) or was not given at all (control group).

\section{REFERENCES}

1. Pavan K, Raju BC and Coventry DM (2014): Ultrasound-guided brachial plexus blocks. Continuing Education in Anaesthesia Critical Care \& Pain, 14(4): 185-191.

2. Golwala MP, Swadia VN, Dhimar AA et al. (2009): Pain relief by dexamethasone as an adjuvant to local anaesthetics in supraclavicular brachial plexus block. Journal of Anaesthesiology Clinical Pharmacology, 25(3):285.

3. Robaux S, Blunt C, Viel E et al. (2004): Tramadol added to $1.5 \%$ mepivacaine for axillary brachial plexus block improves postoperative analgesia dose-dependently. Anesthesia \& Analgesia, 98(4): 1172-1177.
4. Alemanno F, Ghisi D, Fanelli et al. (2012): Tramadol and $0.5 \%$ levobupivacaine for singleshot interscalene block: Effects on postoperative analgesia in patient undergoing shoulder arthroplasty. Minerva Anestesiol, 77:1-2.

5. Kaabachi O, Ouezini $\mathrm{R}$, Koubaa $\mathrm{W}$ et al. (2009): Tramadol as an adjuvant to lidocaine for axillary brachial plexus block. Anesth Analg, 108:367-370.

6. Kumar S, Palaria U, Sinha AK et al. (2014): Comparative evaluation of ropivacaine and ropivacaine with dexamethasone in supraclavicular brachial plexus block for postoperative analgesia. Anesthesia, Essays and Researches, 8(2):202.

7. Shrestha BR, Maharjan SK, Shrestha S et al. (2007): Comparative study between tramadol and dexamethasone as an admixture to bupivacaine in supraclavicular brachial plexus block. JNMA. J. Nepal. Med. Assoc., 46(168):158-164.

8. Dayer P, Collart L and Desmeules J (1994): The pharmacology of tramadol. Drugs, 47(1):37.

9. Lehmann KA (1997): Le tramadol dans les douleurs aigue"s. Drugs, 53(2):25-33.

10. Arcioni R, Rocca M, Romano`S et al. (2002): Ondansetron inhibits the analgesic effects of tramadol: a possible 5-HT3 spinal receptor involvement in acute pain in humans. Anesth. Analg., 94:1553-7.

11. Tsai YC, Chang PJ and Jou IM (2001): Direct tramadol application on sciatic nerve inhibits spinal somatosensory evoked potentials in rats. Anesth. Analg., 92(6):1547-1551.

12. Mert T, Gunes $Y$, Guuen $M$ et al. (2002): Comparison of nerve conduction blocks by an opioid and local anesthetic. Eur. J. Pharmacol., 439: 77-81.

13. Güven M, Mert $T$ and Günay I (2005): Effects of tramadol on nerve action potentials in rat: comparisons with benzocaine and lidocaine. Int. J. Neurosci., 115: 339-349.

14. Yalcin I and Aksu F (2005): Involvement of potassium channels and nitric oxide in tramadol antinociception. Pharmacology Biochemistry and Behavior, 80(1):69-75. 
15. Mert T, Gunes y and Guany I (2007): Local analgesic efficacy of tramadol following intraplantar injection. Eur. J. Pharmacol., 558:68-72.

16. Goel SN, Daftary SR and Pantavaidya SH (2002): Intravenous regional anesthesia using tramadol hydrochloride and ketorolac: a double blind control study. Indian J. Anaesth., 46(5): 369-372

17. Shin HW, Ju BJ, Jang YK et al. (2017): Effect of tramadol as an adjuvant to local anesthetics for brachial plexus block: A systematic review and meta-analysis. PloS. One, 12(9):184-149.

18. Serhan Y, Bulent H, Volkan E et al. (2012): Tramadol as an adjunct for levobupivacaine in axillary plexus blockade: A prospective, randomized, double-blind study. Turkish Journal of Medical Sciences, 42. 55-62.

19. Chatopadhyay S, Mitra LG, Biswas BN et al. (2007): Tramadol as an adjuvant for brachial plexus block. J. Anaesth Clin. Pharmacol., 23:187-9.

20. Mannion S, O'Callaghan S, Murphy DB et al. (2005): Tramadol as adjunct to psoas compartment block with levobupivacaine $0.5 \%$ : a randomized double-blinded study. Br. J. Anaesth., 94: 352-356.

21. Antonucci S (2001): Adiuvanti nel blocco del plesso brachiale per viaascellare: confronto tra clonidina, sufentanil e tramadolo. Minerva Anestesiol., 67:23-27.
22. Geze S, Ulusoy H, Engin E et al. (2012): Comparison of Local Anesthetic Mixtures with Tramadol or Fentanyl for Axillary Plexus Block in Orthopaedic Upper Extremity Surgery. Eur. J. Gen. Med., 9(2):118-123.

23. Kapral S, Gollmann G, Waltl B et al. (1999): Tramadol added to mepivacaine prolongs the duration of an axillary brachial labor pain plexus blockade. Anesth. Analg., 88 (4): 853-856.

24. Sarihasan B, Kiziroglu C, Tu“ r A et al. (2002): Supraclavicular plexus blocs with tramadol _ bupivacaine and bupivacaine. Eur. J. Anaesthesiol., 19(24): 1-398.

25. Siddiqui AM, Hany AG, Abdulmohsin AI et al. (2008): Tramadol as an adjuvant to intravenous regional anesthesia with lignocaine. Saudi Medical Journal, 29: 1151-1155.

26. Kaushik T, Ghai A, Kundu ZS et al. (2016): Evaluation of new approach to ultrasound guided stellate ganglion block. Saudi Journal of Anaesthesia, 10(2):161-166.

27. Dikmen B, Gamli M, Horasanli $\mathbf{E}$ et al. (2009): The effects of adding tramadol to ropivacaine on axillary brachial plexus blockade in uremic patients. Turk. J. Med. Sci., 39:733739.

28. Senel AC, Ukinc $O$ and Timurkaynak A (2014): Does the Addition of Tramadol and Ketamine to Ropivacaine Prolong the Axillary Brachial Plexus Block? Bio. Med. Research International, 2014:281-287. 